Article

\title{
Protected Areas, Tourism, and Rural Transition in Aysén, Chile
}

\author{
Heidi Blair ${ }^{1, * \mathbb{D}}$, Keith Bosak ${ }^{1}$ and Trace Gale ${ }^{1,2}$ \\ 1 Department of Society and Conservation, University of Montana, Missoula, MT 59812, USA; \\ keith.bosak@umontana.edu \\ 2 Department of Sustainable Tourism, Center for Patagonia Ecosystem Investigation, Coyhaique 5951369, \\ Chile; tracegale@ciep.cl \\ * Correspondence: heidi.blair@mso.umt.edu
}

Received: 15 November 2019; Accepted: 6 December 2019; Published: 11 December 2019

\begin{abstract}
Following global trends, nature-based tourism in the Aysén region of Chilean Patagonia has grown dramatically in recent years. This growth has challenged traditional economic activities derived from commodification of natural resources, including ranching, logging, and mining. A qualitative research study conducted in 2016-2017 used semi-structured interviews and focus groups to investigate how local residents perceived the changes that accompany rural development around the nationally protected area of Cerro Castillo, projected to be one of the region's protected areas that will drive economic development through tourism in coming decades. Results identified several themes reminiscent of the rural transition that took place in the western United States in the mid to late-1900s. During this era, the remote, rugged, wild frontier lands of the sparsely populated intermountain west shifted from an economy grounded in extractive industries to a service-based one, geared towards amenity migrants and tourists seeking recreation opportunities and closeness to nature. Patterns and lessons are drawn between similar transitions across geographies and timescales, which may assist planners with understandings of trends and tendencies as tourism continues to influence rural transition in Patagonia.
\end{abstract}

Keywords: protected area; tourism; rural transition; perceptions of change; Patagonia

\section{Introduction}

Peripheral rural communities with cultural identities linked to abundant and accessible natural resources for extraction and production have experienced livelihood transitions during the past century, primarily because of changing development policies created by central governments [1-15]. Historically, central governments used concessions, land grants, tax breaks, and other policies to incentivize pioneer settlers to occupy remote and isolated parts of their countries as a strategy to increase occupation and territorial claims in areas with scarce government presence. Pioneers and their descendants forged strong ties to these lands, which were intertwined with livelihood strategies based on available natural resources, such as ranching, timber harvesting, and mining. Over time, centrally driven development policies have evolved in many places to incorporate an increasing emphasis on conservation and the establishment of national protected areas.

Legal designation of public lands as national parks, reserves, wilderness, etc. marked the beginning of this new era, which was accompanied by use restrictions and increasing bureaucracy for settlers living in adjacent areas [8]. During the twentieth century, modernist development paradigms and rising environmental consciousness have fostered the expansion of national protected areas around the world [6,7]. Once remote and isolated protected areas have become zones of focus for policies that 
promote tourism, recreation, and other forms of leisure-related development, deemed as compatible with conservation.

These changes are major drivers of change in the periphery. They are often met with local resistance as conservation-based economies and service-oriented jobs displace traditional work, which has been historically and intimately tied to rural identities. In some places, local community attitudes and reactions about surges in protected area tourism are well chronicled, but transitions in central Patagonia have not yet been connected to these patterns despite extensive similarities. The focus of the study is the Cerro Castillo National Protected Area (CCNPA), located in the Aysén Region of Chile. The CCNPA, originally designated a National Reserve in 1970 and upgraded in status to National Park in 2017, provides a particularly rich case study for consideration of how the transition from expansionist to conservation-based development policies changes lives at the local level, helping to identify important elements to improve the feasibility of currently proposed sustainable development alternatives to natural resource extraction.

\subsection{Rural Transitions: Public lands, Tourism and Amenity Migration}

Rural transitions of the late 20th and early 21st century have been well-documented in the United States (US) West. These patterns of transition, however, are not limited to this region; they resemble those in other peripheral and rural mountain regions worldwide $[8,16,17]$. This section outlines some of the patterns of transition that have occurred in the US West and elsewhere in order to establish a common pattern of rural transition. This pattern has been associated with broader structures of modernity and capitalism and can be characterized as a regime shift from the production and consumption of natural resources to that of experiences [18]. Essentially, working landscapes shift toward conservation/recreation landscapes.

Much research and discussion in the US West has focused on immigration of people searching for scenic beauty and recreational opportunities [8]. This process is referred to as rural gentrification and involves Post-industrial Middle Class (PMIC) amenity migrants [18]. Amenity migration, however, is an outcome of a constantly evolving history that is predicated on the changing role of national public lands. Places that once provided natural resources for production (minerals, timber, grasslands for grazing) have evolved, providing settings that are now attractive for recreation and tourism, spurring population growth.

Multiple forces drive this era of rural transition. While local in nature, globalization influences conditions greatly. As Gosnell and Abrams noted: "A major driver of this change is global trade liberalization, which has allowed developed countries to outsource the production of food and fiber to less developed countries rather than relying on domestic production" [6] (p. 307). Economies of areas that once produced such goods are no longer competitive in a global market. Decline in production in rural areas weakens economies and leads to out migration of longtime residents, setting the stage for demographic transitions.

Simultaneously, culture in modern and capitalist societies has shifted towards the "consumption of lifestyles, identities, culture and leisure" [6] (p. 307). Rural areas, particularly in mountain regions, are attractive to such consumers. They offer attributes that resonate with their values, including closeness to nature, recreation, leisure and opportunity for escape. Therefore, public lands, such as national parks, reserves and forests, adjacent to rural communities, often play a key role in rural transitions. Winkler et al. [19] (p. 480) noted: "The public lands that comprise a large portion of this geography are of central importance to these economic and cultural transformations. Traditionally important as a source of commodity production, the more contemporary emphasis on preservation and protection of public land resources has helped to attract growing numbers of in-migrants and seasonal residents seeking naturally beautiful settings." In addition, the US government has been a longtime promoter of tourism on public lands [20].

Tourism and recreation associated with national public lands has long been a major driver for economic growth in many rural 'gateway' communities in the US [19,21]. These same trends have been 
increasingly observed and documented in other parts of the world, including ever more remote corners and peripheries [22]. Tourism is also a driver of amenity migration around the world, as tourists shift from short-term rental accommodations to seasonal residences and ultimately full-time living [23]. In the context of rural gentrification, Hines [18] used the term 'permanent tourist' to describe such amenity migrants: "the term 'permanent tourists' ... is a conceptual hybrid that demands that we appreciate not only the analogy between the activities of rural gentrifiers and those of traditional tourists but also the fact that rural gentrifiers are pursuing these activities in a regular and constant fashion" [18] (p. 509).

In the US West, amenity migration to rural areas has defined and cemented the demographic and economic transitions [24]. These shifts have been accompanied by changes in human relationships to land, as well as a disruption of traditional cultures. As formerly productive landscapes have given way to landscapes of leisure, conservation and consumption, rural communities across the globe have frequently struggled to maintain their identities [25]. In addition, as more people (primarily the PMIC) have migrated to these rural areas and introduced their own values, the characteristics that were responsible for attracting that growth in the first place have been threatened. As Nygaard and Bosak noted in relation to the US West: "the fundamental challenge for many rural counties in the West is not only how to economically develop but how to symbiotically maintain economic and demographic change with a community's ongoing social, cultural, and environmental heritage" [26] (p. 236). The current study in Aysén sought to understand how rural communities surrounding the CCNPA have perceived and responded to this fundamental challenge, and how the lived experiences in this area of Patagonia contribute to the larger patterns that are repeated across many peripheral geographies.

\subsection{Context of the Case Study}

The CCNPA is located in Aysén, the third-largest yet least populated region in Chile. It is situated within the north-central reaches of the Patagonia cultural zone, which spreads across the southernmost parts of South America, in Argentina and Chile (Figure 1). While Argentinean Patagonia consists mainly of grasslands and pampas, the terrain in Chilean Patagonia is much more diverse, characterized by towering peaks, glacier-filled fjords, sheep and cattle ranches, lush forests, lakes, and raging rivers. The CCNPA is one of eighteen national protected areas in the Aysén Region that form part of the National System of Natural Protected Areas (SNASPE), which is administered by the Chilean National Forestry Corporation (Conaf). Situated close to the regional capital of Coyhaique and the airport in Balmaceda, this is one of the most accessible parks in the region (Figure 2).

The CCNPA was established on June 19th, 1970, with 179,550 hectares comprising three separate sectors [27]. Surrounding population centers include Coyhaique $(57 \mathrm{~km}$, population 44,850$)$, Balmaceda (35 km, population 456), El Blanco (20 km, population 305), Puerto Ingeniero Ibáñez (30 km, population 757), and Villa Cerro Castillo (5 km, population 500) [27]. Dispersed rural populations live near Lago Monreal, Lago La Paloma, and Villa Frei [27]. Administratively, the CCNPA is inserted within the municipalities of Coyhaique and Río Ibáñez and the provinces of Coyhaique and General Carrera. It was established as a National Reserve based on the existence of forests that fit the definition of Forest Reserve, with interests in protecting its beauty and its scientific and botanical importance [27]. More specifically, the resources the CCNPA seeks to conserve are its flora, fauna, geologic features, soil, and water.

The main ecosystems represented include alpine montane, forest, and steppe. Important flora species include lenga, ñirre, coihue, ciruelillo and the calafate, and important fauna species include the huemul, puma, guanaco, and red fox [28]. The huemul, or south Andean deer, is a charismatic species in Chile. It is an endangered species threatened by habitat loss and fragmentation (from land conversion, road construction, and human settlement), predation, hunting, and disease-transfer from domestic livestock [29]. The CCNPA is an important stronghold for huemules, though the IUCN identifies unregulated tourism as a threat to the population [28]. Twenty-five kilometers of 
the Pan-American Highway, known locally as the Southern Highway [Carretera Austral], bisect the CCNPA, passing through the heart of important habitat for huemul and other native wildlife.

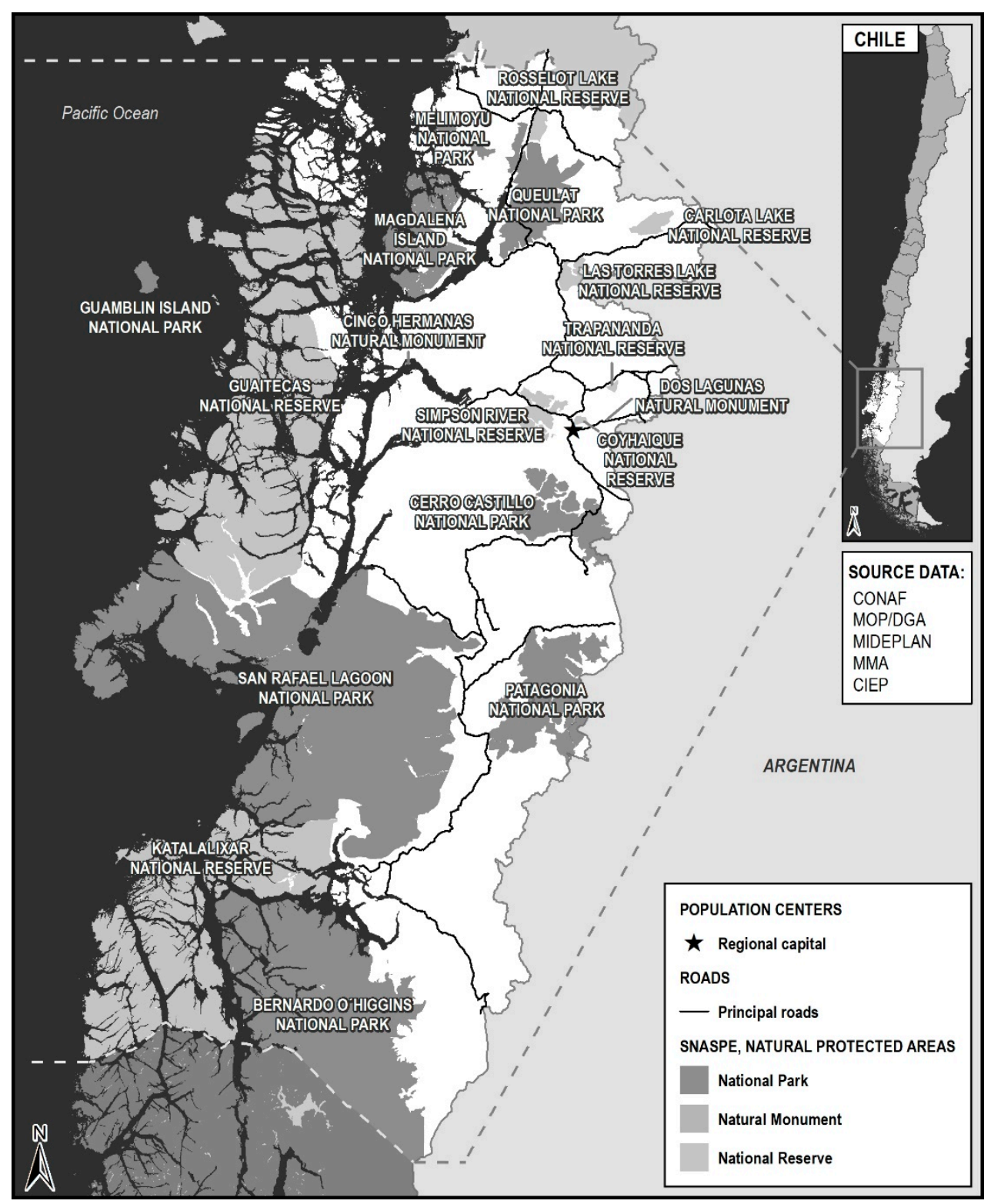

Figure 1. Map of the Aysén Region of Chile, indicating national protected areas, including the Cerro Castillo National Protected Area (CCNPA).

The namesake of the CCNPA is a towering, jagged, rocky spire visible from Villa Cerro Castillo, the main gateway community. This town of $~ 500$ people is the heart of the "frontside" of the CCNPA, which refers to the easily accessed eastern side that is reachable from the main highway. Primary livelihood activities include ranching, tourism, commerce, and public services. The "backside" of the CCNPA refers to the western side of the park, where rough, winding dirt roads connect isolated rural farms and a few tourism lodges located in the Monreal, Paloma, and Desierto lake sectors, and the tiny villages of El Blanco, Valle Simpson, and Villa Frei. Recreation opportunities in the CCNPA include hiking, backpacking, climbing, and more, with major attractions including glaciers, turquoise lakes, high mountain passes, old-growth forests, and wildlife [30].

Conaf's records of annual visitation show steady increases for the CCNPA. Apart from 2012, each year between 2007 and 2016 recorded steady growth. This is a 733\% increase over ten years. 
Actual visitation numbers are likely significantly higher than those presented in the official records, as the entrances to the CCNPA are not consistently staffed and visitors also enter at undesignated points [30]. (See Table 1)

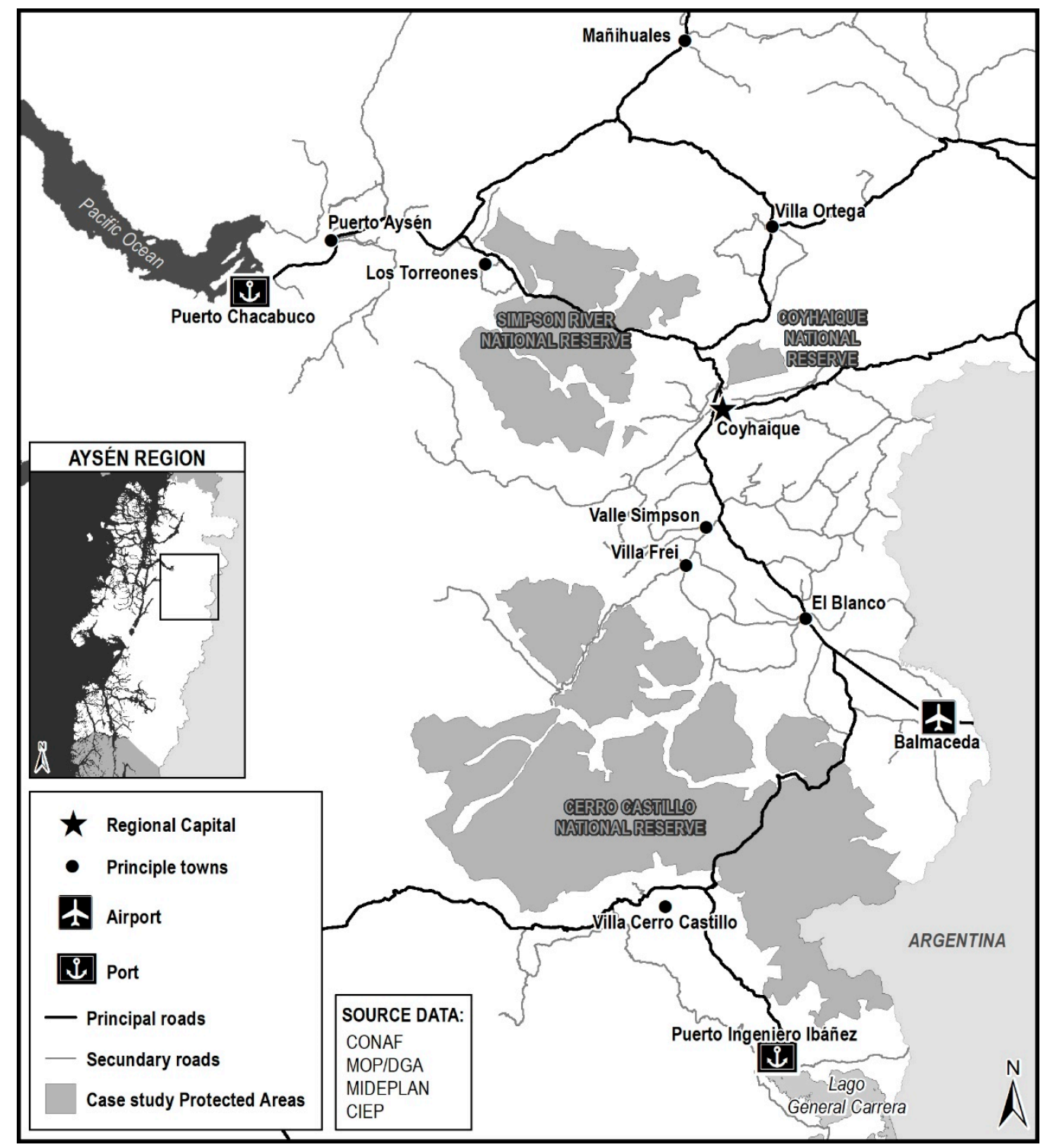

Figure 2. CCNPA and buffer communities, as they are situated in the regional context.

Table 1. Annual Visitation to the CCNPA, 2007-2016.

\begin{tabular}{ccccccccccc}
\hline Visitor Group & $\mathbf{2 0 0 7}$ & $\mathbf{2 0 0 8}$ & $\mathbf{2 0 0 9}$ & $\mathbf{2 0 1 0}$ & $\mathbf{2 0 1 1}$ & $\mathbf{2 0 1 2}$ & $\mathbf{2 0 1 3}$ & $\mathbf{2 0 1 4}$ & $\mathbf{2 0 1 5}$ & $\mathbf{2 0 1 6}$ \\
\hline National & 348 & 549 & 781 & 918 & 1487 & 1017 & 2358 & 1650 & 1906 & 3752 \\
Foreign & 265 & 456 & 552 & 257 & 436 & 558 & 535 & 473 & 917 & 1397 \\
Total & 613 & 1005 & 1333 & 1175 & 1923 & 1575 & 2893 & 2123 & 2823 & 5149 \\
\hline
\end{tabular}

Based on current tendencies and several policy-based strategies and tactics, visitation to the CCNPA and its surrounding areas is expected to continue to increase rapidly during the coming years for five primary reasons [29,30]. First, the Chilean National Tourism Law No. 20.423, enacted in 2010, recognized tourism as a strategic pillar for economic and social development in rural and remote communities [31,32]. Second, the Chilean strategy, imposed subsequent to the adoption of this law, 
has employed tactics to disperse tourism spending beyond traditional urban centers to remote areas of the country that offer spectacular landscapes, primitive settings, and a high concentration of public protected lands [31,33]. For example, the 2010 tourism legislation established models that prioritized tourism concessions in SNASPE PAs, supported by governance systems that spread decision-making amongst several ministries with oversight from the Ministry of Economy, Development and Tourism. This change marked a significant policy change with respect to the role Chilean PAs play within economic development strategy. It shifted decision-making about the number and scope of concessions within PAs, diminishing Conaf's management and controls in favor of a consortium of agencies that are led by a ministry with a tourism and economic development focus. Third, the nationally funded Special Development Plan for Extreme Zones (PEDZE) of 2014 provided Aysén the potential to receive more than $\$ 700$ million USD between 2016-2022 for infrastructure and capacity building projects with a major focus of fueling tourism sector growth. The strategy prioritized the development of a unique tourism offer based on the region's incredible natural resources, its concentration of protected areas, and the potential for tourism to spread positive environmental, social, and economic impacts throughout the territory. Fourth, in parallel to the implementation of PEDZE, the Chilean national Subsecretary of Tourism prioritized the area surrounding the southern reaches of the CCNPA as having high tourism potential by identifying it as a Zone of Interest for Tourism (ZOIT) [33]. The ZOIT designation expands the attention given to this area, sending a message nationally about its potential and priority as a tourism development zone.

Fifth and finally, on March 15th, 2017, Tompkins Conservation, a private international conservation foundation with significant private protected areas in Chile, and then President, Michelle Bachelet, signed a Protocol of Agreement announcing the creation of a "Network of National Parks of Chilean Patagonia" [34]. The proposed network was one of the terms specified for the donation of Foundation lands and infrastructure, converting these private parks to Chilean National Parks, and incorporating them within the existing SNAPSE system. Other terms included the creation and reclassification of other SNASPE protected areas, elevating their level of protection from National Reserve to National Park, which is the strictest category of protection, within the Chilean system. The CCNPA was one of the National Reserves affected by the March announcement. Less than a year later, on October 2, 2017, then-President Michelle Bachelet signed a decree, officially elevating the category of the CCNPA from a National Reserve to a National Park [34].

These policies and associated projections set the context for the rural transitions taking place in the farms and communities situated in the areas adjacent to the CCNPA. Developing a sense of how these contextual dynamics are perceived and experienced at a local level may help inform communities and policymakers as they seek to implement conservation-based development strategies in a way that respects local culture and identity.

\section{Materials and Methods}

\subsection{Overview and Research Questions}

This study explored local experiences of rural transition by examining local community members and actors' perceptions of changes in the communities around the CCNPA in the Aysén Region of Chile. As central government policies catalyze changes in livelihood practices and sociocultural norms in peripheral areas, life experiences of local residents are affected. Using the CCNPA and its surrounding farms and communities as the zone of interest for the case study presented in this paper, qualitative inquiry focused on understanding local perceptions of the changes taking place in and around the CCNPA, with a focus on understanding local attitudes towards changing development, center-periphery dynamics, and how these can inform local protected area planning processes in the face of change. This crystallized into the following research questions:

- How do local residents and actors concerned with the public use of the CCNPA perceive the changes that accompany of rural development? 
- What do these perceptions reveal about center-periphery dynamics in Chile?

- How can these perceptions inform protected area management in areas experiencing rural transitions?

\subsection{Research Design and Justification}

The nature of these questions led to the use of qualitative methods, which were an appropriate way to design an exploratory study about perceptions of a situation layered with many perspectives and influences [35,36]. Creswell [37] explained: "those who engage in this [qualitative] form of inquiry support a way of looking at research that honors an inductive style, a focus on individual meaning, and the importance of rendering the complexity of a situation" (p. 4). The questions sought to understand the experiences of people living the rural transition and policy shifts within the context of their social and interpersonal environments. Accomplishing the objectives of this research was not a matter for systematic tools of measurement, but one of meaning. Research followed a case study approach, based on methodological precepts and constructivist assumptions. Simons [38] defined this approach as: "an in-depth exploration from multiple perspectives of the complexity and uniqueness of a particular project, policy, institution, program or system in a 'real life' context" (p. 21). Stake's case study ontology was employed, which viewed reality as being subjective; requiring a holistic treatment and the recognition that elements are intrinsically linked [39]. The current research project reported in this paper incorporated Stake's ontology by seeking to understand the rural transitions taking place around the CCNPA from a variety of contexts [39]. Specifically, 36 participants (see Figure 3) contributed perspectives for this case study, including the contexts of key informants (PA administrators, regional planners and researchers), public use stakeholders within the communities surrounding the CCNPA, and rural residents who did not actively participate in CCNPA initiatives.

The first perceptual context of this case study involved key informant interviews with three Conaf officials at the local and regional level, five members of an independent research institution (CIEP) that had been contracted to coordinate the development of the 2017 CCNPA Public Use Plan, and a municipal mayor for areas adjacent to the CCNPA (see Figure 3). These interviews were conducted with two objectives. First, interviews sought to understand the context and perspectives of CCNPA administrators, local area researchers, and public use planners. Second, these interviews were used to develop initial sample lists for subsequent stages of data collection. Specifically, the process facilitated the invitation to participate in community focus groups held to inform the creation of the 2017 Public Use Plan (PUP) for CCNPA. Participant observation of these groups enabled the data collection related to the second main segment of this study. Moreover, participating with the researchers responsible for the creation of the 2017 Public Use Plan (PUP) for CCNPA facilitated access to participant groups and immediate credibility within the surrounding communities, while also guaranteeing the results would immediately inform planners and managers. Additionally, these interviews yielded access to secondary documents that were important to the study, including the 2009 CCNPA Management Plan, regional policies and strategies, prior internal research, and institutional knowledge.

Thus, the second portion in the data collection involved local residents and actors within the areas surrounding the CCNPA who elected to participate in the creation of the PA's 2017 PUP. Data collection involved notes and transcripts of three focus groups held as part of the CCNPA PUP planning process, which included the perceptions of a total of 19 actors (See Figure 3). Focus groups provided an efficient way to gather a lot of information from many people in a relatively short period of time, which was an important condition for the planning process. They are useful when trying to understand "the range of ideas or feelings that people have about something," and "to uncover factors that influence opinions, behavior, or motivation" [40] (p. 19). Focus groups also enabled the exploration of "related but unanticipated topics as they [arose] in the course of the group's discussion" [41] (p. 148). This was particularly valuable for identifying the different perceptions and perspectives, and how they intersected and deviated from one another. The conversations that took place during the focus groups 
also highlighted areas of conflict and areas of shared interests in a way that would not have surfaced in individual interviews.

\begin{tabular}{|c|c|c|c|c|c|}
\hline ID & Gender & Time in Aysén & Data Collection Method & Livelihood \& Technical Profile & Sector/s of Interest \\
\hline 1 & Male & $\begin{array}{l}\text { I.ifelong } \\
\text { resident (IR) }\end{array}$ & Key Informant Interviews & $\begin{array}{l}\text { CCNPA administrator, conservation \& public use } \\
\text { manager }\end{array}$ & CCNPA, adjacent communities \\
\hline 2 & Female & $>20$ years & Key Informant Interviews & Regional PA conservation \& PUP professional & CCNPA, adjacent communities \\
\hline 3 & Male & $5-10$ years & Key Informant Interviews & Regional PA conservation \& PUP professional & CCNPA, adjacent communities \\
\hline 4 & Female & $10-20$ years & Key Informant Interviews & Regional PA researcher \& PUP professional & CCNPA, adjacent communities \\
\hline 5 & Male & 10 - 20 years & Key Informant Interviews & Regional PA researcher \& PUP professional & CCNPA, adjacent communities \\
\hline 6 & Male & LR & Key Informant Interviews & Regional anthropologist \& cultural specialist & CCNPA, adjacent communities \\
\hline 7 & Male & $10-20$ years & Key Informant Interviews & $\begin{array}{c}\text { Regional nature-based tourism (NBT) development } \\
\text { \& planning specialist }\end{array}$ & CCNPA, adjacent communitiess \\
\hline 8 & Male & $10-20$ years & Key Informant Interviews & Regional NBT operations \& logistics expert & CCNP $\Lambda$, adjacent communities \\
\hline 9 & Male & LR & Key Informant Interviews & Municipal Mayor adjacent to CCNPA & CCNP $\Lambda$, adjacent communities \\
\hline 10 & Male & LR & $\begin{array}{l}\text { VCC Concessionaire Focus } \\
\text { Group (FG) }\end{array}$ & $\begin{array}{l}\text { Landowner adjacent to CCNPA, Potential } \\
\text { concessionaire - camping services }\end{array}$ & VCC side of CCNPA \& adjacent lands \\
\hline 11 & Female & $5-10$ years & VCC Concessionaire FG & $\begin{array}{l}\text { Landowner adjacent to CCNP } \Lambda \text {, Potential } \\
\text { concessionaire - Trail maintenance, camping, } \\
\text { guiding \& related services }\end{array}$ & VCC side of CCNP $\Lambda$ \& adjacent lands \\
\hline 12 & Male & LR & VCC Concessionaire FG & $\begin{array}{l}\text { Landowner adjacent to CCNPA, Actual } \\
\text { concessionaire - Trail maintenance, camping, } \\
\text { guiding \& related services }\end{array}$ & VCC side of CCNPA \& adjacent lands \\
\hline 13 & Male & $\mathrm{LR}$ & VCC Community FG & $\begin{array}{c}\text { Representative of Villa Cerro Castillo (VCC) } \\
\text { Neighborhood Association }\end{array}$ & VCC side of CCNPA \& adjacent lands \\
\hline 14 & Male & LR & VCC Community FG & Resident of VCC & VCC side of CCNPA \& adjacent lands \\
\hline 15 & Male & $5-10$ years & VCC Community FG & $\begin{array}{c}\text { Representative of a rural capacity development } \\
\text { NGO working in VCC }\end{array}$ & VCC side of CCNP $\Lambda$ \& adjacent lands \\
\hline 16 & Male & LR & VCC Community FG & Resident of VCC & VCC side of CCNPA \& adjacent lands \\
\hline 17 & Female & LR & VCC Community FG & $\begin{array}{c}\text { Representative of a rural capacity development } \\
\text { NGO working in VCC }\end{array}$ & VCC side of CCNPA \& adjacent lands \\
\hline 18 & Male & LR & VCC Community FG & Resident of VCC & VCC side of CCNPA \& adjacent lands \\
\hline 19 & Female & LR & VCC Community FG & $\begin{array}{l}\text { Landowner adjacent to CCNPA, President of the } \\
\text { Professional } \Lambda \text { ssociation of Rural Tourism in VCC }\end{array}$ & VCC side of CCNPA \& adjacent lands \\
\hline 20 & Male & $>20$ years & VCC Community FG & Landowner adjacent to CCNPA, Regional Senator & VCC side of CCNPA \& adjacent lands \\
\hline 21 & Male & LR & Coyhaique Community FG & $\begin{array}{l}\text { Tourism Development for a Municipality adjacent } \\
\text { to CCNPA; Regional Cultural Expert }\end{array}$ & CCNPA \& adjacent communities \\
\hline 22 & Male & LR & Coyhaique Community FG & Patagonia Andean Mountain Sports Club & CCNPA, especially Bombacha Sector \\
\hline 23 & Male & LR & Coyhaique Community FG & $\begin{array}{l}\text { Landowner adjacent to CCNPA, mountain guide \& } \\
\text { regional tourism operator }\end{array}$ & $\begin{array}{c}\text { Monreal Lake Sector of CCNPA \& } \\
\text { adjacent lands }\end{array}$ \\
\hline 24 & Male & LR & Coyhaique Community FG & $\begin{array}{l}\text { Regional rancher, Representative of Foundation to } \\
\text { Preserve the Huemul }\end{array}$ & CCNPA \& adjacent communities \\
\hline 25 & Male & $>20$ years & Coyhaique Community FG & $\begin{array}{l}\text { Regional representative a Chilean NGO dedicated } \\
\text { to conservation of native flora \& fauna }\end{array}$ & CCNPA \& adjacent ecosystems \\
\hline 26 & Male & $>20$ years & Coyhaique Community FG & $\begin{array}{l}\text { Regional professional planner \& technical expert for } \\
\text { Chilean National Roads Authority }\end{array}$ & $\begin{array}{l}\text { CCNPA \& Southern I lighway } \\
\text { (Route 7) Corridor }\end{array}$ \\
\hline 27 & Male & $>20$ years & Coyhaique Community FG & $\begin{array}{l}\text { Regional professional planner \& technical expert for } \\
\text { Chilean National Roads Authority }\end{array}$ & $\begin{array}{l}\text { CCNPA \& Southern Highway } \\
\text { (Route 7) Corridor }\end{array}$ \\
\hline 28 & Male & I.R & Rural Sector Interviews & $\begin{array}{l}\text { I andowner adjacent to CCNPA, livelihood includes } \\
\text { ranching, rural tourism, \& firewood extraction }\end{array}$ & $\begin{array}{l}\text { Blue I.ake [I ago Azul] Sector of } \\
\text { CCNPA \& adjacent lands }\end{array}$ \\
\hline 29 & Female & LR & Rural Sector Interviews & $\begin{array}{l}\text { Landowner adjacent to CCNPA, livelihood includes } \\
\text { ranching, rural tourism, \& firewood extraction }\end{array}$ & $\begin{array}{l}\text { El Blanco Village \& adjacent sectors } \\
\text { of CCNPA }\end{array}$ \\
\hline 30 & Male & I.R & Rural Sector Interviews & $\begin{array}{l}\text { Landowner adjacent to CCNPA, livelihood includes } \\
\text { ranching \& firewood extraction }\end{array}$ & $\begin{array}{l}\text { El Blanco Village \& adjacent sectors } \\
\text { of CCNPA }\end{array}$ \\
\hline 31 & Female & LR & Rural Sector Interviews & $\begin{array}{l}\text { Landowner adjacent to CCNPA, livelihood includes } \\
\text { ranching \& firewood extraction }\end{array}$ & $\begin{array}{l}\text { Balmaceda Village \&adjacent sectors } \\
\text { of CCNPA }\end{array}$ \\
\hline 32 & Male & LR & Rural Sector Interviews & $\begin{array}{l}\text { Landowner adjacent to CCNPA, livelihood includes } \\
\text { ranching, rural tourism, \& firewood extraction }\end{array}$ & $\begin{array}{l}\text { Simpson Valley, Blue Lake [Lago } \\
\text { Azul| \& adjacent sectors of CCNPA }\end{array}$ \\
\hline 33 & Male & I.R & Rural Sector Interviews & $\begin{array}{l}\text { Landowner adjacent to CCNPA, livelihood includes } \\
\text { ranching \& firewood extraction }\end{array}$ & $\begin{array}{l}\text { Paloma and Monreal Lakes \& } \\
\text { adjacent sectors of CCNPA }\end{array}$ \\
\hline 34 & Female & LR & Rural Sector Interviews & $\begin{array}{l}\text { Landowner adjacent to CCNPA, livelihood includes } \\
\text { ranching \& firewood extraction }\end{array}$ & $\begin{array}{l}\text { Paloma and Monreal Lakes \& } \\
\text { adjacent sectors of CCNPA }\end{array}$ \\
\hline 35 & Male & I.R & Rural Sector Interviews & $\begin{array}{l}\text { Landowner adjacent to CCNPA, livelihood includes } \\
\text { ranching \& firewood extraction }\end{array}$ & $\begin{array}{l}\text { Simpson Valley, Blue Lake [Lago } \\
\text { Azul| \& adjacent sectors of CCNPA }\end{array}$ \\
\hline 36 & Female & IR & Rural Sector Interviews & $\begin{array}{l}\text { Landowner adjacent to CCNPA, livelihood includes } \\
\text { ranching, rural tourism, \& firewood extraction }\end{array}$ & $\begin{array}{l}\text { Escalada Sector \& adjacent sectors of } \\
\text { CCNPA }\end{array}$ \\
\hline
\end{tabular}

Figure 3. Study participant profiles.

Participants were identified with the goal of representing maximum variation in terms of livelihood interests (ranching, tourism, conservation, etc.), and geographic dispersion (representing the different 
communities that surround the protected area). Groups took place in Coyhaique and Villa Cerro Castillo. Coyhaique, located approximately 20 miles from the backside of the CCNPA and 50 miles from Villa Cerro Castillo, is the regional capital and headquarters for many of the actors involved in the development of the 2017 PUP for the CCNPA. Eight people participated in the Coyhaique group, which was held in a meeting room at the CIEP research center. Participants represented a range of actors and interests, including government professionals, tourism operators, ranchers, and recreational user groups.

Villa Cerro Castillo is the main gateway community, and this town of 400 people has emerged as a center of tourism development, with a few of the most popular trailheads beginning near the town center. Local actors who lived in or nearby to Villa Cerro Castillo had expressed high levels of interest in the evolving 2017 Public Use Plan. For this reason, two focus groups were organized in Villa Cerro Castillo. One was specifically designed with the objective of talking with actors who were in the process of developing concession agreements with the CCNPA. It consisted of three influential tourism actors, based in the Villa Cerro Castillo area, and was held in one of their quinchos, or rustic cabins near one of the main trailheads. The other was held at the community center in town and open to all who were interested; eight people attended.

Lastly, individual or household level, semi-structured interviews were employed to capture the perspectives of rural residents living in the more remote areas surrounding the CCNPA. These residents were chosen because they typically did not participate in activities or initiatives related to the CCNPA, and their perceptions added important missing perspectives. Seven semi-structured interviews were held with a total of ten people (see Figure 3; one local politician was also interviewed individually as part of this phase). Interviews were primarily held in people's homes but in a few cases at offices or an alternate meeting place identified by the interviewee. In accordance with Singleton and Straits [42], interviews followed a set of predetermined questions designed to obtain information about specific topics, while also allowing the interviewer the flexibility to follow up with probe questions or new ones altogether. This is an appropriate technique for research about perceptions of change because the open-ended questions provide space for people to offer information the researcher may not know to ask about and to explain more completely their viewpoints about complex issues [43].

While the data collection process and format differed for each of the three contexts of the study, they shared many commonalities, as recommended by Stake [39] that facilitated the holistic treatment of this case study, including its subjective realities and intrinsic links. Data collection for each of the three contexts began with the invitation to share participant backgrounds and experiences with the CCNPA. These histories were followed by questions oriented to explore the values, perceptions, and lived experiences of participants, regarding livelihoods, technical skills and strategies, relationships, histories and changes they were observing in their communities and the CCNPA. All the participants were asked to share their preferred future scenarios for the CCNPA and its integration with the surrounding area.

\subsection{Data Processing}

During February 2018, Spanish audio recordings of the interviews and focus groups were transcribed and subsequently translated to English. Rather than a literal, word for word translation, text was translated to maintain the speaker's intended meaning and context. Participant comments were accepted at face value, although elaborations of certain comments were requested for clarification during initial coding and subsequent triangulation stages. These transcripts and the participant-observer notes taken during focus groups were initially coded during March 2018, using a process that involved multiple stages of discovery and interpretation, and a naturalistic paradigm $[39,44]$. Initial coding resulted in twelve sub-themes, grouped into two primary reflections. During October and November 2019, a second stage of analysis focused on triangulation of the original themes amongst the three-member research team for this paper. Additional documents and artifacts were analyzed in order to add richness and context to the emergent themes $[39,44]$. These documents included regional and national policy and strategy documents, publicly available database registers, brochures, newspaper 
and magazine articles, as well as historical and contemporary Chilean essays focused on regional livelihoods, center-periphery dynamics, and change. Their consideration helped to add robustness to the contexts gained during data collection, facilitating a more integral understanding of livelihood activities, policies, discourse, and demographics, within the context of the study. Following this stage, member checking was employed to resolve doubts and ensure merit and consistency for the final categorical themes and conclusions [35,38,39].

The outcomes of this study have been produced in a valid, reliable and ethical manner, following the methodological guidance of qualitative experts [35-42]. The methods employed included multiple forms of triangulation, member checking, peer review, reflexivity, adequate engagement in data collection, maximum variation sampling strategies, audit trails, and thick description. Informed consent and IRB consistent principles of confidentiality were employed whenever data was collected beyond a public setting.

\section{Results}

The following sections represent a brief overview of the study results. The first section focuses on 12 categorical themes that resulted from the coding and aggregation of the data. Next, narratives elaborate on how these themes emerged as lived experiences for local residents and actors, in the communities surrounding the CCNPA.

\subsection{Thematic Results}

Data coding and aggregation yielded 12 categorical themes relevant to the research questions presented. Each of these themes relates to an aspect of the rural transition occurring around CCNPA. (1) Economic/Livelihood Shifts refers to the decline of extractive industries and ranching and the growth of tourism, real estate development, and the service industry. (2) Increasing Visitation corroborates statistics of more visitors coming to the area. (3) Desire for Locally Driven Development highlights visions for the future that tourism should embody local cultural values and style, while enhancing local economic opportunities. (4) Appeal to Amenity Migrants documents conditions appealing to amenity migrants such as desirable land, recreation opportunity or potential, and scenic value. (5) Center Periphery Disconnects reveals the high level of local uncertainty about central government regulations, their power to override their own rules, and belief that the central government does not have the periphery's best interests at heart. (6) Ranching as Cultural Identity demonstrates how deeply intertwined ranching is to identity for many local and the conflicts between conservationists and ranchers. (7) Trust and Outsiders outlines the aura of mistrust of people from outside the region and their intentions, referring to both Santiaguinos and foreigners. (8) Changing Land Values connects the potential for economic benefits from tourism to transform attitudes towards conservation, beginning to value protection rather than see it as a waste. (9) 'Growing Pains' refers to the lack of preparedness in terms of service offerings and protected area infrastructure, highlighting the adjustments necessary and potential areas of conflict such as access through private lands. (10) Actual/Potential Community Displacement documents the ways in which local communities experience redevelopment and arrival of amenity migrants while also documenting the extensiveness of outsiders buying land around CCNPA. (11) Actual/Potential Sources of Conflict (Tourism versus Ranching Juxtaposition) gathers insights from both sides of the ongoing, tense debate about tourism as a threat to ranching. (12) Actual/Potential Power and Income Disparities show the inequities that arise from an imbalance of financial capital, leaving some locals with few options and outsiders who exercise control because of money and power. Figure 4 provides samples excerpts from the data for each of the twelve categorical themes. 


(1) Economic / Livelihood Shifts
"Because the communities have not been trained in tourism. The people who provide horseback riding, lodging, food and information services in
small communities have done so out of necessity. They have done it because it is better than the price of wool, because the farms are no longer so
productive, because the price of the animals varies so much that, in the end, they don't earn as much money. Because the costs for their children to
study have increased, so the family has to generate more income. So, there is a diversity of factors that forced, so to speak, many local people to
work in tourism, which was a sector that they didn't necessarily know."
"Ranching is disappearing, small farmers are disappearing, young people who want to work in the farms are disappearing, they are looking for
another job."
"It's just that there's a lot of land that has been parceled. And in the parcels, well, ranching is not their strong suit. Since everything has already
becn divided into parcels; livestock need to have alarger area, so that there is a good infrastructure, for cxample, to cut hay, you have to have good
barns. In a parcel, what will it have? On the other hand, the parcels can support smaller things. And have livestock, but, only a little. Enough for
tourism, so the people can see the shearing, for example. But not on a large scale, because in a farm of 50 or 20 hectares they are not going to be able
to develop ranching sufficiently to support a family. There can be ranching, but it needs to be accompanied by tourism so that there are other extra
incomes, to make the most of the land."
(2) Increasing Visitation

\section{(2) Increasing Visitation}

"But the quantity of visits has increased, every year it's increasing, and it's going to continue to increase; it's because the attractiveness, there is a lot of dissemination, SERNATUR promotes the region, for better or for worse, but they have done it..."

"What we have talked a lot with the team is to create conditions that will benefit the communities, that will be an incentive for visitors to visit the communities. If we provide more trails, the people will probably stay longer in the communities or they will like the communities more, or some
people in the communities will become guides, or the restaurants will have more demand, the lodges, the camping areas; that is our vision, to do people in the communities will become guides, or the restaurants will have more demand, the
more things that can generate income from the Reserve or be productive for the community."

"Without a doubt, there has been, in the last five or six years, a notable increase in people coming to see the lagoon....and that it will continue...it's recently starting here.

\section{(3) Desire for Locally-Driven Development}

"Tourism is a type of economy that can be very useful for inhabitants to maintain their culture, and to maintain their economic forms. When you're making a typical dish, it's not the same to make a marinated rabbit and a lamb roast... Because the rabbit never belonged to our culture...we would give rabbit to the dogs. But lamb IS part of our culture....and therefore we should never stop raising sheep...there has to be a consistency between culture and , economy."

"On the other hand, the small concessions give an opportunity for the local system to develop...By allowing smaller concessions, you are going to allow the participation of local people, and the integration of these people into real development. And I'm not saying: 'no, we don't want development,' we don't want concessions within the wilderness area - there can be concessions within the wilderness area, but on a small scale; so that allows local actors to have a kiosk for example, or the restrooms; and that's perfect development for the local people. It is not for these other people, who invest billions of dollars, that most likely after those billions of dollars enter
they will leak back out; instead, this is left here in the region."

"I imagine the community participating in everything that relates to a Reserve. And that the community is also a tourist attraction, preserving its traditions. I feel that not only is the Reserve attractive, but the community is also attractive because of its local traditions. And for the same reason, I believe that, as I said before, the Reserve is an asset of the community. So it would be wonderful, I know that it is a very ambitious dream, but that the community will even concession the park, and it advises itself through dialogue. Then, it would be the community itself that could concession the use of the park, with the advice of third parties who were technical experts in management, but that the community would be more cmpowered with regards to the park."

(4) Appeal to Amenity Migrants

"In Monreal Lake...up there they sold one farm that was later subdivided by an association, and it has been sold to a lot of people in Santiago. They have lots all along the shore of the lake, and the people that have bought, they don't have anything yet, they haven't done anything. Others have built, yes. Others have cabins, but others have just bought. But there are many foreigners who have bought the farms and they've left them to the same people."

"In fact, they made million-dollar investments, like making a mountain bike circuit on both sides, and as you can see, they totally cleared the land, took out all the trees, not leaving anything."

" $\Lambda$ long-term project in the area of winter tourism, is that the eastern side of the slope of the Ibáñez Pass, lends itself to development - I was looking - there are some spectacular ski runs, so, the logical thing is also to look at it as potential - winter tourism could complement that of the summer.

\section{(5) Central - Periphery Disconnects}

"The truth is, I see [the elevation to a Park] as an opportunity, because increasing the type of protection of a public land is always good. But, at the same time, we don't know anything about the plans, and we're the main people using the Reserve."

"Maybe I'm a bit uninformed on the subject of the Red de Parques Nacionales, or the new network or this new announcement. To me, it seems like another centralist imposition. Because I have spent time listening to this and I've never heard of in any occasion of being invited to a table like this to see what it is we would want out of a network. So yeah, the announcement that was made in Pumalín with Tompkins really grabbed my attention. With the president of the republic signing a commitment with the lompins, on the backs of the inhabitants of the region of $\Lambda y s e n$ who, in the end, are the ones who are going to have to coexist with this network. I, and many people, see it as a centralist imposition. I don't know what benefits this obtains for the local tourism industry. Because evidently, it opens up more opportun
opportunities for foreign companies to exploit. So yeah, I believe that they skipped a step again."

"The issue is that with the legislation we have today, neither Castillo, nor Jeinimeni, nor Tamango, could be National Parks, mainly because we have exotic tree plantations within these protected areas. $\Lambda$ nd in a National Park, because of the conditions you need to have for the Park category, they don't fit into that category."

"I.ook, I would be ashamed, I would be ashamed, as a local. As I said, I was born and raised here, Cerro Castillo is not the same as a Park here, with the characteristics that Cerro Castillo Reserve has. Why? Because the whole northern area has, I don't know how many thousand, hectares of pine, which is an introduced species, that is, it is not native. So what should we do, put the label Park on Cerro Castillo - as the first Pine Park? If we do that, 'what madness!' some conservationist is going to say, he's going to say: 'what madness struck the person who did this -- what a stupid thing
to do'."

(6) Ranching as Cultural Identity

"So nowadays, the Ministry of Agriculture has all these development programs for improving our pastures, our livestock, our barns, our feed, our hay - so what they did before in an extensive form, today [with these new programs] they can concentrate. So, there is a cultural theme, there's a cultural theme that always, every spring, I go to leave my animals [in summer pastures], they raise themselves alone, [and in fall] I go to look for not even a hundred."

"The other areas of the Reserve are largely unknown. Since people have to first pass through private sectors, they don't enter because most of the properties have signs that say, 'Do not enter. It's forbidden to enter. And that's because the old settlers are no longer there. The old settlers never closed the way to anyone. There was an understanding within the community that even though, in fact the roads were private, they were for public
use. So, there was no problem of passage. What had to be respected was that if the gate was closed, it had to be left closed. If it was open, it had to be left open."

"This [the change from National Reserve to National Park] will surely bring us many problems with people from the surrounding areas who believe that livestock management should still be extensive. I think that point hasn't been handled, no, no... we [CONAF] do not have political clout either because livestock has never, never been priorized lower than conservation. And every time there is an opportunity for the politicions to say 'good, ok, let he animals in [to the PA]'-they have given it to them. They've given it to them! Because it's politics, it's not real need. I do not believe those ranchers need the summer pastures [in the PA]."

Figure 4. Cont. 
(7) Trust and Outsiders

[Speaking about a private foundation that has recently come to Villa Cerro Castillo offering private support for the community to help them develop tourism infrastructure and capacities]: "Independent of the vision that many people in the community might have that this could be something negative, or, Who is this gentleman'?, or 'What does he bring to the table?, Patagonians, as it is, we are distrustful. When you converse with the people [in the community], they say: 'No, this gentleman wants to buy land,' or, 'He is imposing things, like Tompkins did, or, 'Because they have a lot of money, when they come, they going to do this...If you like it, they'll do it, and if you don't like it, they'll do it
anyways.' So, this vision that they come to impose something is also in the community."

[Speaking during a community focus group session for the Public Use Planning of the Reserve]: "Maybe I'm a bit skeptical about on the subject of the Route of the Parks Network; it seems to me that it is another centralist imposition. Because I have spent time listening to this |the controversy over how decisions about the Reserve's future are being made] and I ve never heard in any occasion of being invited to a table like this to see what it is we would want out of a network. So yeah, the announcement with Tompkins and the President of the Republic signing a commitment with the people; it really catches my attention because it's on the backs of the inhabitants of the region of $\Lambda$ ysén who, in the end, are the ones who are going to have to coexist with this network."

\section{(8) Changing Land Values}

"If they know that they are receiving benefits from the protected area, they are going to stop seeing it as a lost territory that could be full of cows, or that they could be with their chainsaws cutting the Reserve into pieces, or, I don't know, doing something with another resource that could be have them as allies, so that they commit themselves to their territory, and we don't appear as the bad guys who are protecting a territory and they
can't even obtain a concrete benefit. In the end, what's benefitting the communities at this moment? The Reserve is only benefitting the people who can't even obtain a concrete benefit. In the end, what's benefitting the communities at this moment? The Reserve is only benefitting the people who
are promoting tourism; for $80 \%$ of the communities, apart from having a beautiful place and a topic of conversation, I don't know..telling that they are promoting tourism; for $80 \%$ of the communities, apart from having
have a protected area next door? They don't receive a direct benefit.

"Without that option many young people go to the city...but with tourism they stay around longer. Because here there are beautiful landscapes that do not exist in other parts of Chile. So you appreciate it here. We don't appreciate them much because we were born here and we have always seen them. But when you travel, to Argentina, for example, you see those huge pampas that don thave a single tree, don thave a single plant, don thave a stream, then you really miss your region. Or you go north in Chile, from Puerto Montt to the north it's also different, the people are different, everything is different".

\section{(9) 'Growing Pains'}

"Basically, the Reserve is our goose that lays golden eggs, so to speak. In the sense that it is the only and grand attraction that we have which is seen, up close it is even more attractive, but it is the most striking. Without a doubt, there has been, in the last five or six years, a notable increase in people coming to see the lagoon.... and that it will continue...it's recently starting here. This- the tourism here is in diapers, so to say. In five
more years, or six more years, hope that all these issues we are seeing are resolved so everything will go well, that there aren't these stops- what is more years, or six more
private, what is public."

" $\Lambda$ bove all, there must also be some kind of incentive for the owners of the properties adjacent to the Reserve on the part of the State so that people will help take care of them. And also incentives for them to provide services to visitors. Because if a person passes through the Reserve, it's hard people could offer that."

"We are not prepared to receive large numbers of tourists within the Reserve. If they decide to run a promotion, many more tourists can enter or arrive. And they don't understand the problems that can bring to the Reserve."

\section{(10) Actual/Potential Community Displacement}

"That's what's wrong. Here we are the settlers of this region. In the past in Simpson Valley almost everything was related to us. Everyone was my uncle or great-uncle; today very few of my relatives are left because the farms were divided and they began to sell to the big companies.

" $\Lambda$ nd the gringos, well the foreigners, there are a lot of plots that owned by foreigners."

"Well, I don't know if it's a gringo, others say it's one of those Turks that comes from Israel. I don't know, but there are some of them that don't get it, because they're snatching up [land] here in Paloma Lake, at the entrance to Paloma Lake. And they are already landowners in Cerro Castillo, because they bought the land from the Ramirez association, the one that reaches La Rionda, the part that s almost adjacent with the other little part that I told you about that's by Paloma Lake, and I'm going to tell you where these gringos are from that say they are gringos; they're Turks, I don't know, whatever the hell, whatever it is. And the other thing, they bought up the other side of $\Lambda$ zul Lake. The part where the Sotos are, where there
used to be various settlers, yeah, they bought it all from them."

\section{(11) Actual/Potential Sources of Conflict (Tourism versus Ranching)}

"What I want, and my vision for the future with the Reserve ... I would also for all sectors, including my own property, to have right of ways for all the different categories. For all standards. Where there is a vehicle road, let it exist, let it be a public road. Where there are trails for horses and trails for pedestrians, so that people can do what they want to do, and the access is free. liree access. And also free access to any public use area."

"[Q]: What do you think of the possible change from Reserve to Park?" [A]: "To a Park? A Park is more limited. [Q]: "In what sense?" [A]: "The truth is that everything is still so premature, I'm sure that three, four, five, who knows how many years will pass for it to become a Park, because that part is just surfacing. I know it's more limited...well, I think it is - I don't know...so as, not to lie." [Q]: "So, that's your opinion though?" [A]: "Yes, that it's more risky than it is now. The Park demands more; so you have to really understand how they are going to manage things. I think that they will work at the level of pure concessions, the park. And it's stricter. Like, as a Reserve, there's more freedom." [Q]: "Like for doing things with
animals? Is that what you mean?" [A]: "No, things with... CONAl' has already eliminated everything that was for grazing, the parts of the Reserves, so that's already out... but I know that it's easier to work the way it is now, than when it's a Park, because the park is more limited in that sense. There's more control, there's more-- I don't know. But that's the opinion I have, based on what I read it in the newspaper."

"What I feel at least is that with regulations that are based on local reality, with rules based on local reality and local experience, I believe that very good ordinances or very good rules can be developed. But if we are going to base ourselves on ordinances that come from the central level and that do not adjust to our reality, they are of no use to us. That is to say, the ideal is that the rules originate from a common agreement between the same
settlers and CONAF itself, that it is in a face-to-face meeting where CONAF tells us that they are interested in us helping them with this. And we settlers and CONAF itself, that it is in a face-to-face meeting where CONAl tells us that they are interested in us helping them with this. And we say,

'We want you to help us with this', and work together. Because obviously we are interested in maintaining and preserving the Forest Reserve Because it is also part of our common future, we share a common space."

\section{(12) Actual/Potential Power and Income Disparities}

"Now we have divided the sectors because the people were impoverished and they sold. 'There was no money, there was nothing; it was a very big crisis. So the people didn't have the 500 hectares they used to have; instead, they had 50, or 20, nothing more... Sometimes the farms were distributed between big families, with ten brothers. And they said, 'What am I going to do with this? and they sold it; so the big businessmen--now
there are the new rich, the Puchis."

"Nlso, you need to understand that the local population who lives off the resources provided by their farms. So, how beautiful it would be if, suddenly, every time a lenga tree falls, as a product of the wind, CONAli itself goes, marks it, and tells the settler, 'You can do with it what you want, in other words, take it and use it.' Every year trees fall and are blocking the route and I can't use them because they belong to CONAF, because they are inside the Reserve. And the family is dying, sometim
because all the firewood that it had left was rotten and of poor quality."

"It's the same as the problem with horseback riding. It's the same problem! It's like they have a loudspeaker because everyone listens to them, because everyone listens to them, but when you say, and how many are there? Three, four, five, ten. So, the proportions are not adequate.

"I think my son likes tourism and our land provides opportunities for tourism because there are very high areas and pure forests. But, we need to have a trail, apply to get projects [public funding] and make trails. And, it's already the case that you can't extract anything else because it is prohibited; things are different now that it is a Reserve. Before, I put cows there and I harvested a little firewood. All that ended with the Reserve that is for tourism now."

Figure 4. Rural transitions themes and sample excerpts. 


\subsection{Narrative Results}

The following three narratives are focused on the research questions and are intended to detail some of the ways in which study participants experienced the twelve themes presented within the prior section [45]. Each provides context that helps explain local perceptions of rural development and associated changes. The first deals with inheritance practices, livelihood shifts, and new landowners. The second highlights the central government's role in changes in changes in land ownership. The third highlights the factor of outside influences, which affected many local perceptions of changing conditions.

The composition of rural land ownership is changing around the CCNPA, with many factors contributing to this transition. Two of these were highlighted by respondents. First, Chilean land inheritance laws and practices traditionally divide all landholdings amongst the remaining spouse (who retains 50\%), and any adult siblings (who divide the remaining 50\%) at the time of the landowner's death. When the remaining spouse passes away, his/her lands are then divided in the same manner. Each time, this division produces smaller and smaller land parcels which are held between a greater number of titles. Since the original Patagonian land grants were sizable, this system typically provided enough land for heirs to maintain ranching-based livelihoods for the first couple of generations. Nevertheless, today many of the founding families in the sector of the CCNPA are entering their fifth generation (or more), and Chilean inheritance laws and practices have proven inadequate for the maintenance of enough landmass in terms of ranching livelihoods.

This has led to two possible outcomes: either the land has been sold or livelihood viability and practices have changed. The smaller land parcels that result from inheritances have a higher scenic valuation than productive value; thus, most families who choose to remain living in parceled lands are forced to diversify their livelihood practices beyond ranching. Some continue ranching on a small scale and incorporate services related to cultural tourism: for example, they may invite visitors to witness sheep shearing, camp on their lands, and participate in a typical event, such as a lamb roast. Thus, ranching activities convert into an attraction for cultural tourism, rather than a primary income generation strategy. Many heirs, however, decide not to maintain these parcels. Some are already living and working elsewhere and prefer to sell to liquefy the value of their inheritance. Others decide the remaining parcels are not viable for maintaining preferred livelihood practices. These smaller land parcels, located adjacent or near to nationally protected lands, appeal to outsiders interested in tourism development, as well as amenity migrants attracted to the scenic value, recreation potential, and space for construction of second homes or hotels. An eager market of buyers exists, ready to make different use of these spaces.

A second primary factor driving land ownership change around the CCNPA is the government's rejection of historic land claims that predate the establishment of the protected area in 1970. This narrative highlights inconsistencies between the center and periphery, and the lived experiences that emerge when central authority has superseded local interests. Before the creation of the CCNPA, the settlers and their descendants have occupied spaces within this area as summer grazing pastures for several decades, but they lacked legal titles proving ownership. Some had provisional titles or permission to occupy, but they did not formally own the land they or their families had settled. In the late 1960s, as part of the agrarian and rural reform policies implemented by the presidency of Eduardo Frei Montalva, area residents were requested to pay to have these lands surveyed formally and to petition for official titles through a central government decree. Following the establishment of the CCNPA in 1970, the recently elected socialist president, Salvador Allende Gossens, only recognized the farms that possessed these new titles. This move aligned with his policies that renationalized many Chilean resources in favor of cooperative land management and a redistributive agrarian platform.

The settlers' summer pasturelands, now within the boundaries of the CCNPA, were not incorporated within property titles, even though the residents' claim to them preceded the establishment of the CCNPA. Many complained to regional authorities; in particular, residents of the Azul Lake sector, on the western side of the CCNPA. In 1988, during the military dictatorship of Augusto Pinochet Ugarte, Conaf, at a regional level, agreed to fund the work of another surveyor, who traveled to the contested 
area to resolve these conflicts. Based on his findings, Conaf (at a regional level) agreed to remove these lands from the CCNPA, citing poor ecological quality of soils and absence of forests. Conaf's maps of the CCNPA at this time appeared with the areas in question removed, but the maps of the Ministry of National Assets (MNA) never incorporated the changes. In the early 2000s, when residents complained about the discrepancy, they recall Conaf telling them to raise the issue with MNA, and vice-versa. Eventually, the lands were surveyed a third time. The periphery based CCNPA advisory council ruled in favor of the locals, recommending that central Chile relinquish property rights to the summer pasturelands. Ultimately, however, the central government rejected this decision and ordered the lands remain within the CCNPA. This outcome, along with increasingly globalized beef and cattle markets, prompted many of these families to sell their land, based on their assessment that ranching would no longer be viable without access to their summer pastures within the CCNPA.

Again, value shifted from productive land use toward amenity consumption. Newcomers quickly absorbed the farms, eager to invest in speculation opportunities, tourism development, or planned communities for amenity migrants. These outsiders possessed the will and financial capital to pursue these types of development, which most local residents did not have. This imbalance generated apprehension towards the outsiders, who were seen as usurping opportunities for economic development that local residents viewed as rightfully theirs.

Local residents expressed frustration with centrally-driven agendas and feeling a lack of control in decision-making related to the CCNPA, further evidenced by some people's attitudes about the Network of National Parks of Chilean Patagonia. The vision of the network, developed by the international NGO, the Tompkins Foundation, and endorsed by Chilean president Michelle Bachelet, is to promote development based on conservation by establishing a world-renowned nature-based tourism route linking protected areas throughout Patagonia. The route is likely to attract more visitors to Villa Cerro Castillo and the other communities surrounding the CCNPA.

Nevertheless, some of the participants, including those who worked in tourism, expressed frustration and distrust at not being included in the conceptualization or process of establishing the network. One local resident, who works in tourism, expressed that even though the Tompkins Foundation designed the project to enhance economic development through tourism, he felt exasperated by the lack of consultation before implementation. He presumed the project would create opportunities for larger companies run by outsiders rather than enhancing local businesses. Stakeholders commonly expressed this type of suspicion and criticism about outside agendas, exemplifying the sensitive central-periphery dynamics that mark rural transitions around the CCNPA.

Furthermore, as mentioned previously, the Tompkins Foundation donated significant private land holdings to the Chilean government to be incorporated within the SNASPE system, on the condition that some protected areas in the region, including CCNPA, be upgraded in protection status from National Reserves to National Parks. The central government in Santiago unilaterally imposed this decision. Residents of the CCNPA's zone of influence, both those in favor and in opposition to the recategorization, critiqued the lack of community engagement in the decision-making process. At the time of data collection in May of 2017, people expressed doubt and uncertainty that the recategorization would actually happen, speculating that if it ever did, it would be years later. To the surprise of many, President Michelle Bachelet announced the status change to a National Park less than six months later, illustrating another contemporary example of central-level policy dictating outcomes in the periphery.

\section{Discussion}

While much is documented about rural transition and the intertwined debates about conservation versus development in the US West and other parts of the world, less research has focused on how these trends are currently unfolding in South America. Understanding the lived experiences of participants in rural communities situated around the CCNPA in Chilean Patagonia helps to address this gap, illuminating some of the historical dynamics and processes influencing perceptions, interpretations, and responses to change in this context. By situating these results within patterns of rural transition 
across geographies, insights may inform rural development policy or protected area management strategies to enable communities to feel agency and inclusion in, rather than threatened by, these types of transitions.

\subsection{Framework for Comparison across Geographies}

Many of the themes that emerged from the lived experiences of participants in this study echo dynamics that have been documented about rural transitions in the western US. Until the mid-1900s, the sparsely populated intermountain West was perceived as a remote, rugged, wild frontier land and with an economy grounded in extractive industry [46]. During the latter part of the century the economy shifted to a service-based economy, which was geared towards amenity migrants and tourists seeking recreation opportunities and a closeness to nature [6,8]. Over subsequent decades, recreation and tourism sectors have continued to provide viable economic opportunities for communities in the intermountain West of the US, increasingly challenging traditional activities grounded in natural resource use and extraction [6]. These shifts have helped to generate economic-based arguments and incentives for conservation and support of nationally protected areas within surrounding communities in the US West. This occurrence has not been isolated, as Robbins, et al. highlighted, "this region is not unique, but largely reflective of larger-scale socioecological forces playing out in similar ways around the postindustrial world" [8] (p. 356).

Results of the current study suggest that the evolving tourism industry in CCNPA and the Aysén region may follow a similar course to that of the US West. This growth is fostered through policy and programming, both at a central level and within local communities. Tourism and protected area visitation in and around the CCNPA are on a high growth trajectory that is projected to continue to surge for the foreseeable future. The parceling of lands and decline of ranching as a viable rural livelihood option facilitate shifts to tourism and amenity-based relocation. This growth is likely to fuel additional diversification of the local economy away from natural resource extraction, towards recreation, conservation, tourism, and related services that appeal to shifting demographics.

When analyzing these types of rural transitions, context will obviously elicit different results, but if rural change is imagined as a linear process, the US is much further along in the demographic transition. In the New West, areas with good access to recreation opportunity, nature, wilderness, and open space record the most dramatic increases in population. In the Aysén region, patterns are emerging that foreshadow these kinds of changes, but the shift is less dramatic now. Because of CCNPA's proximity to the airport and therefore easy accessibility relative to other protected areas in the region, it is positioned to grow faster than others with comparable natural value and recreation opportunity. Similarly, amenity migration is developing as outsiders purchase land parcels from descendants of settlers and develop trails, build cabins, etc. on this land. As these outsiders increasingly occupy the area and contribute to economic diversification, they influence local land values, like in the US during the transition from Old to New West.

\subsection{Increasing Understanding of Lived Experiences and Perspectives of Rural Development}

In Aysén, as well as in the Western US, conservation, tourism and ranching have often appeared as oppositional. In Aysén, tourism actors tended to value conservation in the CCNPA, criticizing ranchers as insensitive to environmental degradation. A scrutiny of the historical context and the lived experiences of participants from these two perspectives revealed much greater complexity; which, at its core, rests on questions of central-periphery decision-making and control, or lack thereof. Neighbors and families around the CCNPA who have lived the experience of title denial may judge new land uses as a threat to their cultural identity, interpreting traditional grazing practices as uprooted by the centralized government through tedious, prolonged dispute and broken promises. Though their anger and mistrust for the denial of their historic land claims is directed at the government, it seemed to also manifest as frustration with new neighbors who build mountain bike trails, guesthouses for tourists, or second homes for amenity migrants, and are seen as replacing the old ways. 
Stakeholders who shared conservation perspectives described a different lived experience. Their stories expressed a prevailing perception of being alone, fighting an uphill battle against the destruction of biodiversity and ecosystems, without appropriate resources and political backing. Their experiences highlighted commitment to the protection of local endangered species, such as the huemul, by prioritizing ecosystem health and biodiversity protection above cultural heritage or productive development. These participants argued that the timeframe for grazing and ranching traditions around the CCNPA is relatively short: modern settlement dates only from the late 1800s to the early 1900s. For conservationists, this relatively short history called into question the legitimacy of ranchers' arguments that their families have established ranching and pasturing cultural traditions, as in reality, these practices only existed in this place for a few generations. They further justified this position by arguing for a modernization of local ranching practices. Stressing the findings of agricultural scientists in the region, they posed that the use of the high summer pastures is an outdated practice, which puts unnecessary strain on the animals due to the long distances traveled to reach drier, lower quality grasses. This message, however, has not been effectively transmitted to, or perhaps accepted by, ranchers around the CCNPA, perhaps due to their skepticism about outsiders and new perspectives.

A key component of the rural transitions identified in the literature about the US West involves shifting ideologies about economic development. Shumway and Otterstrom described these changing beliefs saying, "the basis for future economic growth and development lies not with the exploitation of natural resources, but with the exploitation of the natural environment as a place" [7] (p. 493). Shifting relationships between residents, the environment, and economic development have been documented as a key component of the rural transitions that have taken place in the US West. In many places, especially those bordering protected areas that have successfully integrated communities in their planning and development, prevailing opinions about the protected areas have shifted from criticisms about productive constraints to increasing recognition and valuation of amenity and biodiversity benefits. Similarly, as tourism and recreation sector activities provide increasingly viable economic opportunities for persons living in the surrounding communities of the CCNPA, many of the participants in the current study believed that these activities would likely continue to challenge traditional livelihoods grounded in natural resource use and extraction.

With this new conception, "the principal driving force in this new economy is environmental quality," which "is encapsulated in such items as an unspoiled natural environment, recreation opportunities, cultural richness, reasonable costs of living, safe communities, and quality public services" [7] (p. 493). These natural amenities draw visitors or migrants, and people begin to see that policies that "favor timber harvesting over scenery, mining over water quality, or intensive livestock grazing over wildlife habitat might actually inhibit rather than expand economic growth" [46] (p. 160). This is a key component of the Old West to New West transformation, as protected lands come to be seen as economically beneficial. This trend is beginning around the CCNPA, and conservationists hope it will continue to progress in this direction, abating resistant attitudes from some locals.

\subsection{Stakeholder Perceptions and Central-Periphery Dynamics}

Although the timing and forms have differed, there are several similarities between the central-periphery dynamics that have accompanied rural transitions in the US West and Aysén. In the US, federal expansionist policy provoked a western migration of settlers who established communities and strongholds centered on extractive activities like ranching, timber harvesting, and mining [47]. Later, abrupt changes were made in federal policy, ending the homesteading era and removing enormous tracts of lands as federal public reserves. The US West was violently opposed to the centrally imposed Federal Land Policy and Management Act, manifesting anger and frustration in what is now referred to as the Sagebrush Rebellion. This resentment has been passed down through generations of people that have inhabited western lands, and is still present, in diminishing intensity, within the distrust and conflict witnessed in stakeholder relations. For much of the 20th century, 
the Chilean central government promoted policy and incentives to eliminate forest cover in favor of livestock development in Aysén [48,49].

This development discourse, linked to an American West style of colonization, began to undergo a substantial turnaround in the late 1980s and early 1990s with the neoliberal development model driven by the centralized Pinochet regime $[48,49]$. This was marked by strong economic liberalization, development of modern roads and transportation infrastructure, and the emergence of an active market around tourism products and nature conservation. According to Núñez \& colleagues (2014), the implementation of this model has had a strong impact on land ownership, restructuring it based on strong speculation. They identified deep social impacts within peripheral Aysén communities, produced by central policy changes. Specifically, the figure of the "pioneer" or "settler," and the patriotism associated with questing to this remote area to establish Chile's claim, virtually disappeared. Traditional livestock ranching activities were relegated to a second order of priority to activities linked to tourism, conservation, and preservation of nature [48].

Acknowledging similarities between the central-periphery expansionist policies of the US West and Aysén, with regards to rural transitions, affords an opportunity to reflect on the ways in which central-periphery resentment is manifested in and around the CCNPA. Centralized Chilean policy changes associated with expansionism, agrarian reform, nationalization, and economic liberalization had direct, personal, livelihood impacts for local residents in this study, who lost land claims during the establishment of the CCNPA. It is important to consider what these changes have and still mean for local residents and their descendants, especially those whose identities are shaped by and tied to these events and their outcomes. Their stories shared strong sentiments of anger, power disparities, distrust, and conflict. It is not surprising that these lived experiences continue to affect their interest and capacity to adjust to current levels of uncertainty and change.

For those willing to consider a future based on the conservation of the CCNPA, results highlighted a clear desire for a local character to dominate tourism development, in contrast to the mass tourism model of Torres del Paine National Park to the south, or intermountain West towns in the US that have been designed for tourists and amenity migrants. Participants shared concerns that if the future is determined by centralized planning systems, the people who determine the style of development will be those with money and power, like in-migrants with second homes, mass tourism projects, and others, as has been the case in many communities in the New West. These concerns reflected a general frustration and growing anger that was shared by all the participants, about the low levels of power and autonomy they had in relation to top-down change. The Network of National Parks of Chilean Patagonia and the upgrade in status of the CCNPA from National Reserve to National Park marked two timely examples during this study. Residents were angry about not being considered or included in the negotiations that took place between the Tompkins Foundation and President Michelle Bachelet. They were skeptical that their interests had been considered by either party and distrustful about how decisions would unfold at a local level.

As a remote and detached place like central Patagonia becomes increasingly connected, participation in planning is critical to ensuring that tourism reflects local values, culture, and visions for the future. Central government policies that encourage tourism as a strategy for rural economic development must decentralize by elevating local knowledge, needs, and preferences in outlining what kind of development, on what terms, and defining the limits of acceptable impact.

\subsection{Land Management in Areas Experiencing Rural Transitions}

The rural communities surrounding the CCNPA are facing increasing visitation and complexity, as interest and focus on the Park continues to grow. Mounting pressures, arising from demographic and generational shifts, land-use changes, modernization, and centrally driven neoliberal economic policy and laws, are intensifying the risks associated with traditional livelihoods. Yet, as this study indicates, distrust, resistance, and conflict present serious barriers for effective land management and community-protected area integration. The increasing strategic importance of the CCNPA for the 
communities and regions in which they are situated requires improved management effectiveness; yet, recent studies indicate significant and growing systemic risk [50-53]. As indicated in recent research from Gale, Ednie, and Beeftink: "Increasingly, protected areas are concerned with the potential impacts of overtourism, a term used to describe excessive and inappropriate forms of tourism development. Protected area tourism growth is normally accompanied by increased pressure for access, infrastructure, and services; all of which require planning, development, and management. When these processes are adequate and responsible, tourism holds the potential to yield benefits for both protected areas and for numerous groups of stakeholders in the communities in and beyond their limits. Nevertheless, when protected area planning and management processes are ineffective, primary conservation goals can be compromised, leading to negative impacts and increased vulnerability" [54] (p. 1611).

Increasingly, protected area managers must be able to successfully navigate between central and local level processes, finding ways to increase local relevance and integration, in compliance with centrally developed laws and policy. Considering the lived experiences of their local residents and groups is an important first step in this process. For example, while many participants viewed tourism and ranching as being mutually exclusive, others appreciated the potential to preserve grazing traditions through cultural tourism, weaving the two together into a diversified livelihood approach. The gateway town of Villa Cerro Castillo was considered the focal point for immediate tourism-related economic development opportunities and many local residents have transitioned to full-time livelihood practices related to visitor services. Others engaged with tourism as a strategy for livelihood diversification, complementing traditional livelihood activities with tourism-based strategies that offered higher incomes and helped them compensate for decreasing wool prices. CCNPA managers were optimistic that as an increasing number of local residents experienced financial benefits from tourism and conservation-based livelihood strategies, they would place greater value in the CCNPA and develop a growing appreciation for conservation, as a land management strategy. Stakeholders were optimistic that tourism opportunities could potentially slow, or even reverse, trends of youth urbanization, expressing potential for youth to return to their rural communities after completing their studies, and finding greater potential and more appealing work opportunities than before.

Recent public use planning efforts emphasized more holistic and participative processes, with a strategy based on improving experiences, decreasing vulnerability, and better community integration [30]. Further, the CCNPA managers that participated in the current study shared a commitment in finding ways to create conditions that would benefit the surrounding communities. They emphasized building a network of smaller, local tourism operators to support the concessions and increased demand that they anticipated in coming years. They identified potential linkages between additional trail infrastructure within the CCNPA and the length of time visitors spent in local communities. They expressed their preference that lodging and restaurant services be established within surrounding communities, as part of an economic development strategy, and not within the limits of the Park. These tactics were recognized as being important components of developing a social link with the communities and actors within the CCNPA territory. Reasoning that primary sources of conflict arise within these areas, managers expressed a sense of responsibility to provide benefits that would help actors to become allies, sharing in conservation efforts. Other study participants also expressed support for greater integration of the CCNPA within the community, expressing the importance of having Conaf take a more active role in the development of rules and regulations that are based on local realities and experiences. They expressed doubt in the use of central level rules, preferring collaborative, face-to-face processes between Conaf and local actors. Some went further, expressing a preference for community-based management of the CCNPA, in which the community becomes the administrator of the Park, under a concession agreement with the central government, advised by third party technical experts in PA management, like Conaf, but with a more tangible empowerment over decision-making. 


\section{Conclusions}

Limitations of generalizability are inherent within the design chosen for this study. Clearly, the results were localized. The purpose was not to measure or predict, but to develop a better understanding of how local residents and actors concerned with the public use of the CCNPA, situated in the peripheral Aysén region of Chile, perceived livelihood and community change, and how those changes relate to evolving central development policies. The research team included three investigators with lengthy experience in the western United States and in the Aysén Region. Based on Stake's epistemology, the researchers interacted with rural transitions taking place around the CCNPA for a prolonged period of time in order to obtain an insider role and understanding of the human experience. Stake recommended an axiology based on the acknowledgement and acceptance of the values and biases of the research team $[39,42,44]$. Reflexivity involved the recognition that, as residents of the western US (Montana) and of the Aysén Region (Coyhaique) and as researchers in the area of sustainable tourism, the team incorporated holistic worldviews, valuing multiculturalism and multiple forms of knowledge/knowing. Some of the enduring values shared by the team that undoubtedly influenced this case study included an appreciation for wilderness and open spaces, nature-based recreation, freedom, independence, and development based on social, economic, and environmental sustainability.

Other limitations of this study included language issues resulting from a fluent but non-native understanding of the language of the study group, the relatively short period for the collection of field data, a reliance on protected area planning processes for sampling recommendations, and the personal biases and perspectives of the researchers about this topic. To overcome these limitations and the subjectivities, the research incorporated respected methods for improving the validity, reliability, and ethical quality, including multiple forms of triangulation, member checking, peer review, adequate engagement in data collection, and maximum variation sampling strategies.

This research sought to understand the meanings people attached to livelihoods, tourism, conservation, and change within the context of their social and interpersonal environments. There were no standardized instruments developed to measure these meanings. Patton [55] suggested that, "while one cannot generalize from single cases or very small samples, one can learn from them-and learn a great deal, often opening up new territory for further research ... " (p. 46). The lived experiences of the participants in the study suggest that central-periphery policy shifts related to conservation and development can threaten cultural and individual identities, manifesting in individual and community attitudes and responses to change. Moving past deep-rooted resentment, skepticism and distrust will require additional insight and research. Future research should support more holistic processes of protected area planning and management, with the goal of helping to overcome deep-seated conflicts and biases, based on historic and actual lived experiences. Research is also needed to assess the potential for systemic change in the way that central-periphery policy and law is developed and implemented in Chile, and other parts of the world that are affected by similar dynamics. The development of the Network of National Parks of Chilean Patagonia offers a particularly compelling opportunity for researchers who may be able to identify ways in which this initiative can be better positioned at a local level to engage with individuals and communities, so as to move beyond current conflicts and begin to conceptualize how future tourism and amenity-based development will look in their own backyard.

Author Contributions: H.B. conceptualized the original research project, collected the data, conducted the analysis, and was the primary author of the manuscript. K.B. supervised H.B.'s data collection, assisted with analysis, contributed significantly to the literature review, and assisted with editing the manuscript. T.G. contributed significantly to the analysis, was the second-highest contributor of manuscript content, and assisted with editing later drafts of the manuscript.

Funding: This research was supported by the by the Chilean National Commission for Science and Technology Research (CONICYT) under Regional Program CONICYT R17A10002. Additional funding provided by the USDA Forest Service International Programs. 
Acknowledgments: This research was supported by the W.A. Franke College of Forestry and Conservation at the University of Montana in Missoula, Montana and the Center for Patagonia Ecosystem Investigation (CIEP), Coyhaique, Chile. Cartography developed by Andrés Adiego (2019), Department of Sustainable Tourism, CIEP, Chile.

Conflicts of Interest: The authors declare no conflicts of interest. The funders had no role in the design of the study; in the collection, analyses, or interpretation of data; in the writing of the manuscript, or in the decision to publish the results.

\section{References}

1. Vaccaro, I.; Beltran, O. Consuming Space, Nature and Culture: Patrimonial Discussions in a Hyper-Modern Era. Tour. Geogr. 2007, 9, 254-257. [CrossRef]

2. Randelli, F.; Romei, P.; Tortora, M. An evolutionary approach to the study of rural tourism: The case of Tuscany. Land Use Policy 2014, 38, 276-281. [CrossRef]

3. Baker, C. The nation-building state retreats: An Australian case study in the changing role of the state. J. Rural Stud. 2018, 62, 146-155. [CrossRef]

4. Hughes, M.; Jones, R. From Productivism to Multi-functionality in the Gascoyne-Murchison Rangelands of Western Australia. Rangel. J. 2010, 32, 175-185. [CrossRef]

5. Turnock, D. Agriculture in Eastern Europe: Communism, the transition and the future. GeoJournal 1996, 38, 137-149. [CrossRef]

6. Gosnell, H.; Jesse, A. Amenity migration: Diverse conceptualizations of drivers, socioeconomic dimensions, and emerging challenges. GeoJournal 2011, 76, 303-322. [CrossRef]

7. Shumway, M.; Otterstrom, S. Spatial Patterns of Migration and Income Change in the Mountain West: The Dominance of Service-Based, Amenity-Rich Counties. Prof. Geogr. 2001, 53, 492-502. [CrossRef]

8. Robbins, P.; Katharine Meehan, K.; Gosnell, H.; Gilbert, S. Writing the New West: A Critical Review. Rural Sociol. 2009, 74, 356-382. [CrossRef]

9. Wald, J.H.; Temkin, E.H. The Sagebrush Rebellion: The West against Itself-Again. UCLA J. Environ. Law Policy 1982, 2, 187-207.

10. Finegan, C. The Alaska Lands Controversy: A Fight Bigger than the Last Frontier. Georg. Wright Forum 2015, 31, 290-298.

11. Overholser, A. An Examination of Sagebrush Rebellion Communications Using Narrative Policy Framework. Available online: https://digitalscholarship.unlv.edu/thesesdissertations/2718 (accessed on 28 November 2019).

12. Ragsdale, J.W., Jr. The Ozark National Scenic Riverways and the Sagebrush Rebellion in Missouri. Urban Lawyer 2015, 49, 1-65.

13. Wojciechowska, J. Twenty Years of Polish Agritourism: The Past and the Future. Sci. Note 2011, 21, 67-72.

14. Srisomyong, N. Agritourism, Rural Development and Related Policy Initiatives in Thailand. Available online: http://shura.shu.ac.uk/id/eprint/20397 (accessed on 28 November 2019).

15. Bebbington, A. Reencountering development: Livelihood transitions and place transformations in the Andes. Ann. Assoc. Am. Geogr. 2000, 90, 495-520. [CrossRef]

16. Chipeniuk, R. Planning for Amenity Migration in Canada: Current Capacities of Interior British Columbian Mountain Communities. Mt. Res. Dev. 2004, 24, 327-335. [CrossRef]

17. Glorioso, R.S.; Moss, L.A.G. Amenity migration to mountain regions: Current knowledge and a strategic construct for sustainable management. Soc. Chang. 2007, 37, 137-161. [CrossRef]

18. Hines, J.D. The post-industrial regime of production/consumption and the rural gentrification of the New West Archipelago. Antipod 2012, 44, 74-97. [CrossRef]

19. Winkler, R.; Field, D.R.; Luloff, A.E.; Krannich, R.S.; Williams, T. Social landscapes of the Inter-Mountain West: A comparison of "Old West" and "New West" communities. Rural Sociol. 2007, 72, 478-501. [CrossRef]

20. Duchemin, M. Water, Power, and Tourism: Hoover Dam and the Making of the New West. Calif. Hist. 2009, 86, 60-82. [CrossRef]

21. Krannich, R.S.; Petrzelka, P. Tourism and natural amenity development: Real opportunities? In Challenges for Rural America in the Twenty-first Century; Pennsylvania State University Press: State College, PA, USA, 2003.

22. Balmford, A.; Green, J.M.H.; Anderson, M.; Beresford, J.; Huang, C.; Naidoo, R.; Manica, A. Walk on the Wild Side: Estimating the Global Magnitude of Visits to Protected Areas. PLoS Biol. 2015, 13, e1002074. [CrossRef] 
23. Stewart, S. Amenity Migration in Trends 2000s: Shaping the Future-5th Outdoor Recreation $\mathcal{E}$ Tourism Trends Symposium; Luft, K., MacDonald, S., Eds.; Michigan State University: Lansing, MI, USA, 2002; pp. 369-378.

24. Ooi, N.; Laing, J.; Mair, J. Sociocultural change facing ranchers in the Rocky Mountain West as a result of mountain resort tourism and amenity migration. J. Rural Stud. 2016, 41, 59-71. [CrossRef]

25. Abrams, J.B.; Gosnell, H. The politics of marginality in Wallowa County, Oregon: Contesting the production of landscapes of consumption. J. Rural Stud. 2012, 28, 30-37. [CrossRef]

26. Nygaard, K.; Bosak, K. A critical assessment of the Mineral County Challenge: The role and implications of scale in collaborative development. J. Rural Stud. 2014, 34, 235-245. [CrossRef]

27. National Forestry Corporation of Chile (CONAF) \& Division of Natural Protected Areas for the Aysén Region. Management Plan, Cerro Castillo National Reserve; National Forestry Corporation of Chile: Coyhaique, Chile, 2009. (In Spanish)

28. Black-Decima, P.A.; Corti, P.; Díaz, N.; Fernandez, R.; Geist, V.; Gill, R.; Gizejewski, Z.; Jiménez, J.; Pastore, H.; Saucedo, C.; et al. Hippocamelus bisulcus. the IUCN Red List of Threatened Species. Available online: https://www.iucnredlist.org/species/10054/22158895 (accessed on 11 December 2019).

29. Pedrasa, L. Public use in the Region of Aysén. In Visitor Use Planning Methodology Workshop of the National Forestry Corporation (Conaf); Division of Natural Protected Areas, Aysén Region: Coyhaique, Chile, 2016. (In Spanish)

30. National Forestry Corporation of Chile (CONAF) \& Division of Natural Protected Areas for the Aysén Region. Public Use Plan for Cerro Castillo National Reserve; National Forestry Corporation of Chile: Coyhaique, Chile, 2017. (In Spanish)

31. OECD. OECD Tourism Trends and Policies 2014: Chile. In OECD Tourism Trends and Policies 2012; OECD Publishing: Paris, France, 2014. [CrossRef]

32. Gale, T.; Adiego, A.; Ednie, A. A $360^{\circ}$ Approach to the Conceptualization of Protected Area Visitor Use Planning within the Aysén Region of Chilean Patagonia. J. Park Recreat. Adm. 2018, 36, 22-46. [CrossRef]

33. Inostroza Villanueva, G. Sustainable Tourism and Conflict over the Use of Resources. Case Study: Chilean Patagonia, Aysén Region; Universitat Autónoma de Barcelona: Barcelona, Spain, 2016. (In Spanish)

34. Tompkins Conservation. Cerro Castillo Becomes A National Park. Isla Magdalena Expanded. 2017. Available online: http://www.tompkinsconservation.org/news/2017/11/20/cerro-castillo-becomes-a-national-park-islamagdalena-is-expanded/ (accessed on 21 November 2018).

35. Schutt, R.K.; Chambliss, D.F. Chapter 10: Qualitative Data Analysis. In Making Sense of the Social World: Methods of Investigation; SAGE Publications, Inc.: Thousand Oaks, CA, USA, 2013; pp. 320-357. [CrossRef]

36. Yin, R. Qualitative Research from Start to Finish; SAGE Publications, Inc.: Thousand Oaks, CA, USA, 2011.

37. Creswell, J. Research Design: Qualitative, Quantitative, and Mixed Methods Approaches; SAGE Publications, Inc.: Thousand Oaks, CA, USA, 2014.

38. Simons, H. Case Study Research in Practice, 1st ed.; SAGE Publications Inc.: Thousand Oaks, CA, USA, 2009; Available online: https://ebookcentral.proquest.com/lib/msoumt/detail.action?docID=743724 (accessed on 15 September 2019).

39. Stake, R.E. Case Studies. In Strategies of Qualitative Inquiry, 2nd ed.; Denzin, N.K., Lincoln, Y.S., Eds.; SAGE Publications Inc.: Thousand Oaks, CA, USA, 2003; pp. 134-164.

40. Krueger, R.; Casey, M.A. Focus Groups: A Practical Guide for Applied Research; SAGE Publications, Inc.: Los Angeles, CA, USA, 2009.

41. Berg, B. Qualitative Research Methods for the Social Sciences; Pearson Education, Inc.: Boston, MA, USA, 2007.

42. Singleton, R., Jr.; Straits, B. Approaches to Social Research; Oxford University Press: New York, NY, USA; Oxford, NY, USA, 2010.

43. Botterill, D.; Platenkamp, V. Key Concepts in Tourism Research; Sage Publications Ltd.: London, UK, 2012.

44. Boblin, S.L.; Ireland, S.; Kirkpatrick, H.; Robertson, K. Using Stake's Qualitative Case Study Approach to Explore Implementation of Evidence-Based Practice. Qual. Health Res. 2013, 23, 1267-1275. [CrossRef] [PubMed]

45. Nasheeda, A.; Abdullah, H.B.; Krauss, S.E.; Ahmed, N.B. Transforming Transcripts into Stories: A Multimethod Approach to Narrative Analysis. Int. J. Qual. Methods 2019, 18, 1-9. [CrossRef]

46. Hansen, A.J.; Rasker, R.; Maxwell, B.; Rotella, J.J.; Johnson, J.D.; Parmenter, A.W.; Kraska, M.P.V. Ecological causes and consequences of demographic change in the New West. Bioscience 2002, 52, 151-162. [CrossRef]

47. Glasenapp, L. Chasing the Mirage of New Water in the American Southwest. Nat. Resour. J. 2017, 57, 319-320. 
48. Núñez, A.; Aliste Almuna, E.; Bello, Á. The discourse of development in Patagonia-Aysen: Conservation and nature protection as devices of a renewed colonization. Chile, in the XX-XXI centuries. Scr. Nova Rev. Electrónica de Geogr. y Cienc. Soc. 2014, 18. [CrossRef]

49. Miranda Cabaña, F. State policy and the incorporation of space in capitalist geography: The case of Aysén Patagonia. BEGEO 2016, 4, 50-70. (In Spanish)

50. Butler, R. Sustainable tourism in sensitive environments: A wolf in sheep's clothing? Sustainability 2018, 10, 1789. [CrossRef]

51. Kim, Y.; Kim, C.; Lee, D.K.; Lee, H.; Andrada, R.I.T. Quantifying nature-based tourism in protected areas in developing countries by using social big data. Tour. Manag. 2019, 72, 249-256. [CrossRef]

52. Schulze, K.; Knights, K.; Coad, L.; Geldmann, J.; Leverington, F.; Eassom, A.; Burgess, N.D. An assessment of threats to terrestrial protected areas. Conserv. Lett. 2018, 11. [CrossRef]

53. Wilson, S.P.; Verlis, K.M. The ugly face of tourism: Marine debris pollution linked to visitation in the southern Great Barrier Reef, Australia. Mar. Pollut. Bull. 2017, 117, 239-246. [CrossRef] [PubMed]

54. Gale, T.; Ednie, A.; Beeftink, K. Worldviews, levels of consciousness, and the evolution of planning paradigms in protected areas. J. Sustain. Tour. 2019, 27, 1609-1633. [CrossRef]

55. Patton, M. Qualitative Research \& Evaluation Methods: Integrating Theory and Practice, 4th ed.; SAGE Publications, Inc.: Saint Paul, MN, USA, 2014.

(C) 2019 by the authors. Licensee MDPI, Basel, Switzerland. This article is an open access article distributed under the terms and conditions of the Creative Commons Attribution (CC BY) license (http://creativecommons.org/licenses/by/4.0/). 